\title{
Duoguiheyi: Chinese Planning Faces the Test of Integration
}

\section{Martin Tzou, Du Shu and Liu Lidan}

Translator. Michael Black

\section{(2) OpenEdition \\ Journals}

Electronic version

URL: http://journals.openedition.org/chinaperspectives/7176

ISSN: 1996-4617

Publisher

Centre d'étude français sur la Chine contemporaine

\section{Printed version}

Date of publication: 1 March 2017

Number of pages: 15-23

ISSN: 2070-3449

\section{Electronic reference}

Martin Tzou, Du Shu and Liu Lidan, «Duoguiheyi: Chinese Planning Faces the Test of Integration », China Perspectives [Online], 2017/1 | 2017, Online since 01 March 2018, connection on 28 October 2019. URL : http://journals.openedition.org/chinaperspectives/7176 


\title{
Duoguiheyi: Chinese Planning
}

Faces the Test of Integration

MARTIN TZOU, DU SHU, AND LIU LIDAN

\begin{abstract}
Chinese urban planning has recently begun an institutional revolution that seeks to integrate plans drawn up by several ministries. Aimed at giving more coherence to public action, the process of integration, already technically complex, is confronted with a power struggle between administrations, making duoguiheyi difficult to implement.
\end{abstract}

KEYWORDS: urban planning, integrated approach, institutional reform, sustainable cities.

\section{Introduction}

On 26 August 2014, the "Information note on the launching of 'duoguiheyi' (多规合一) pilot projects in towns and districts" (1) was published on the website of the National Development and Reform Commission (NDRC), with duoguiheyi (2) meaning literally "the integration of several plans into one." This directive of the central government in three articles, short, clear, and synthetic, in fact marks a major change of framework in Chinese planning.

Article 1 stipulates that this policy is intended to:

Unify or integrate a number of existing planning processes in a given geographical area, namely: economic and social development planning, urban and rural planning, land use planning, and planning for the protection of the environment. For each district or urban area in China, the objective is now to rely on "a single planning process, a single plan" to eradicate the current situation of compartmentalised planning, which creates conflicts in content and lack of coordination between plans.

In Article 2 appears the watchword that characterises the action of duoguiheyi: "rationalising" four aspects of planning: "durations, objectives, missions, and the coordinating governance of spatial planning." Finally, Article 3 decrees the launching of pilot projects throughout China to implement this policy.

The directive was promulgated jointly by four major ministries, and it is interesting to note the order in which they are cited: first the NDRC, ${ }^{(3)}$ followed by the two ministries MLR and MEP, and only lastly the MOHURD. The order of appearance is never insignificant in Chinese texts, as it reflects the result of arbitration at the top levels of the state. Yet the MoHURD, the most technically legitimate in the integration of plans, is relegated to last in order of appearance, confirming the supremacy of the NDRC as the ministry in charge of duoguiheyi.

In fact, duoguiheyi thus defined can be considered a major shift of paradigm (if not a "revolution") of the Chinese system of planning towards integration. Indeed, since the launch of reforms in 1978 and following China's economic growth, the number of planning exercises has multiplied in a host of domains that concern the cities, at all administrative levels and to various degrees.
Developed and implemented independently of one another, the planning processes of the various ministries are mainly marked by a serious lack of coordination, resulting in major contradictions and hindering the growth processes of cities and districts. The main task of duoguiheyi is therefore to put in place a system to coordinate the various plans and put an end to what has become a chaotic situation.

This central government directive is in fact the culmination of a long process emanating from the local level, since the need for integration has been felt on the ground since the end of the 1990s. Its appearance in official texts thus conversely reveals the lack of integration that has governed spatial planning in China over the last decades. Essentially interdisciplinary, because it aims at a transversal integration of plans, its success necessarily involves vertical reform of the institutions. This "institutional revolution" put in place fully corresponds to the spirit of the "work of general deepening of reform of the central government," (4) which has been the political watchword since $X i$ Jinping and Li Keqiang came to power.

We therefore propose in this article to study this movement, its causes, and its prospects for evolution. We will refer to the official texts of current policies, as well as to the abundant Chinese academic literature on the subject: more than 490 Chinese academic articles and publications have dealt with this subject since 1988, with a significant increase between 2014 and 2015. ${ }^{(5)}$ The sources consulted on duoguiheyi also come from several disciplines, as befits the variety of fields in-

1. National Development and Reform Commission, Guanyu kaizhan shixian "duoguiheyi" shidian gongzuo de tongzhi (Information note on the launching of duoguiheyi pilot projects in cities and districts), 26 August 2014, http: // www. .sdpc.gov.cn / zcfb / zcfbtz / 201412 / t20141205_ 651312.html (accessed on 2 November 2016).

2. In the rest of the article, we will designate the policy of duoguiheyi directly by its name in Chinese pinyin. There will also be references to liangguiheyi, which means "two plans in one," and sanguiheyi, which means "three plans in one." By default, duoguiheyi designates an integration of more than three plans, the most successful and widespread at present being siguiheyi, "four plans in one."

3. The official English abbreviations of the Chinese institutions will be used in the rest of this article: NDRC for the National Development and Reform Commission; MoHURD for the Ministry of Housing and Urban-Rural Development; MEP for the Ministry of Environmental Protection; and MLR for the Ministry of Land and Resources.

4. "Zhongyang quanmian shenhua gaige gongzuo," as quoted in article 1 of the information note from the NDRC.

5. Zhang Yongjiao and Fang Chuanglin, "Kongjian guihua xietiao yu duoguiheyi yanjiu" (Inventory of research on the coordination of spatial planning and planning coordination), Chengshi guihua xuekan, No. 2, 2016, pp. 78-87. 
volved: city planning, the environment, energy, urban geography, political science, etc.

After an analysis of the interplay of the actors and of the various types of plans, the process of integrating the plans and its evolution will be examined through pilot projects of duoguiheyi implemented since the year 2000 , in connection with urban growth. We will then seek to highlight the technical trajectories of integration, as well as attempts at institutional innovations at the local level. Finally, we will explore attempts at planning integration in the field of the sustainable city ${ }^{(6)}$ and its link with duoguiheyi by the yardstick of the "Ecological Civilisation" put forth in the 13th FiveYear Plan.

\section{A complex interplay of actors in a chaotic "layer-cake" of plans}

From the beginning of the planned economy, the Chinese planning system put in place a compartmentalisation of administrations and technical specialties. Over time, inconsistencies have arisen and intensified, with the multiplicity of actors and their competition for resources reinforcing the administrative chaos.

\section{From a single actor to a multiplicity of actors in spatial planning}

As soon as it was established in 1949, the People's Republic of China (PRC) extended to its entire territory a system of planned economy, strongly marked by the Soviet legacy. The National Commission for Planning (Guojia jihua weiyuanhui 国家计划委员会) was the mainstay of this system, with the main objective of industrialising the country and supporting agricultural production through five-year economic plans.

During this period, a single discipline intervened on terrestrial space: urban planning. ${ }^{(7)}$ A clear legal order defined the hierarchy among plans, without antagonism or apparent conflict: urban planning followed the principles and quantified objectives established by economic planning. It was the spatial translation of the latter and the main engine of the urbanisation of the country. ${ }^{(8)}$

Beginning in 1981, the era of reforms initiated by Deng Xiaoping changed the economic structure of the country, and changed the objectives of the planning apparatus. The National Planning Commission became the NDRC in 2003, with the mission of developing the country's macroeconomic policy, and its planning methods evolved. The NDRC's five-year plans expanded to more wide-ranging missions. A series of new subjects emerged: social, energy, transport, education, scientific, and technological problems.

While a prerogative of the Ministry of Construction (which became MoHURD in 2008), urban planning did not escape this phenomenon. At various levels of government, a new series of urban planning schemes appeared: planning networks of cities and towns, strategic urban planning, planning the integration of the rural into the urban, etc. It was also during this period that there emerged land-use planning by the Ministry of Territory and Resources (MLR), as well as planning for environmentally sustainable development by the Ministry of Environmental Protection (MEP). (9) Various ministries and competent administrative authorities developed their own sectorial plans, but this was done in a compartmentalised and silo-like manner. Thus, spatial planning was no longer the prerogative of urban planning. More and more players were involved in it through different types of planning.

\section{Plans organised in a hierarchical way according to "channels"}

The "hyper-pyramidal" (10) system of the Chinese planning apparatus is designed to strengthen the vertical control of power. The whole apparatus can be described as a "hyper-hierarchical and hyper-functionalist" (11) machine. All the national administrations are replicated at all levels of government (provincial, municipal, county-level), responding to and obeying directives drawn up at the central level. In this arrangement, each central administration has its own planning directorate, which develops sectorial plans at each administrative level:

- the economic and social development plans of the NDRC - essentially all five-year plans - define the economic and social objectives as a whole for the future;

- the urban plans of the MoHURD take over the problems related to urban planning at each administrative level;

- the land use plans of the MLR define land use on a regional scale encompassing the city. Their mission is to demarcate and protect agricultural and natural areas: these are the areas where urbanisation should end;

- the sustainable development and environment plans of the MEP issue measures and recommendations for ecology.

We can speak of real "sectors" or families of plans, depending on their sectorial and ministerial lines.

\section{A "layer-cake" of plans}

Currently, there are more than 83 types of plans of a legal value, ${ }^{(12)}$ and more than 200 other categories of thematic "plans" in all sectors of Chinese planning as a whole. ${ }^{(13)}$ The vertical nature of this administrative arrangement makes each level of each administration responsible for the development, approval, and implementation of plans. The number of plans and actors is thus multiplied by so many ministries, in so many provinces and cities in China. This multiplicity of plans, created, promoted, and implemented by so many administrative entities, which differ both in their nature and in their prerogatives, makes the planning apparatus counterproductive. Inconsistencies can be found, for example, in the dates of promulgation or durations of application, as well as technical and normative contradictions. More and more actors are involved in the development and approval process of urban projects. Aware of the power and related interests at stake, administrations have gradually appropriated the planning tool

6. Nicolas Douay and Thuy Cory, "Développement urbain durable en Chine: entre apprentissage et mirage marketing," in Michel Hubert, Paul Lewis, and Michel M. Raynaud (eds), Les Grands Projets urbains. Territoires, acteurs et stratégies, Montréal, Presses de l'université de Montréal, 2014, pp. 239-262.

7. Léon Hoa, Reconstruire la Chine: trente ans d'urbanisme, 1949-1979, Paris, Le Moniteur, 1981

8. Wu Fulong, Planning for Growth: Urban and Regional Planning in China, London, Routledge, 2015, p. 51

9. Gu Chaolin, "Lun zhongguo 'duogui' fenli yuqi yanhua yu ronghe wenti" (On the separation of urban development plans in China, their evolution and their integration), Dili yanjiu (Research in Geography), Vol. 34, No. 4, 2015, pp. 601-613.

10. Rémi Curien, "La planification des villes chinoises, Environnementaliser une machine hyper-fonctionnaliste," Perspectives chinoises, 2014/3, p. 30.

11. Idem, p. 30

12. Cai Yunnan, "Xinshiqi chengshi sizhong zhuyao guihua xietiao tongchou de sikao yu tansuo" (Reflections on the attempt to integrate four main plans of Chinese cities), Guihuashi (Planners), Vol. 25 , No. 1, 2009, pp. 22-25.

13. Gu Chaolin, "Lun Zhongguo "duogui" fenli yuqi yanhua yu ronghe wenti" (On the separation of urban development plans in China, their evolution and their integration), art. cit., p. 605. 
to make it an instrument of control. This situation results in administrative confusion and contradictions between the plans and between the administrative levels intervening in the production of urban space. The whole constitutes a sort of "layer-cake" of plans that has become inoperative.

Reflecting this chaotic situation, an intrinsic competition has gradually arisen between administrations of equivalent rank. Within these administrations themselves, experts' voices were raised as early as 2003, calling for greater integration of the plans. This movement was the origin of duoguiheyi. ${ }^{(14)}$ However, it took some time for these initial calls for coherence to be heard by the central government.

In a way, the duoguiheyi movement can be interpreted as a rejection of the "overflow" of planning on the part of the planning apparatus. The proliferation of plans attenuates the expected macroscopic effects of planning as a whole. In seeking to reduce the number of existing plans, the coordination efforts implemented by the duoguiheyi are meeting for the moment with great resistance on the ground, and are generating a cost-benefit ratio that remains negative overall.

\section{The evolution of the integration of plans}

\section{Urban planning and land use planning: The initial conflict}

Promulgated in December 1988 by the State Council, the "Law on land management" established in China the principle of monetisation of the soil, giving a major impetus to the economic development of the cities. By creating a system of emphyteotic leases, this law marks the beginning of the commercialisation of land in China. This reform had an impact on spatial planning because the allocation of space resources was now subject, on the one hand, to local public action and on the other hand to the emergence of a land market. ${ }^{(15)}$ In this process, urban planning has become the field in which the division of interests between local political and economic powers is negotiated.

According to this "developmentalist" (16) model, urbanisation quickly collided with land-use plans to protect agricultural areas and natural areas. The first conflicts and inconsistencies between these two types of plans emerged in the late 1990s, following the promulgation of a second version of the national land-use plan.

Calls for greater coordination between these two types of plans were heard from professionals and administrations of these two sectors. The implementation of enforcement measures capable of ensuring greater coherence and integration between these two types of plans was then called for.

On the one hand, MLR experts were asking urban planners to use the landuse plan as a reference in order to avoid the pitfalls of feverish and unrestrained urban growth. ${ }^{(17)}$ In response, urban planners defended their historical legitimacy in planning space, and also highlighted the maturity or even the technical superiority of their own planning, and its legal foundations. For planners, coordination between plans is necessary. However, it must be done "seriously," on the basis of rational and scientific arguments. The stakes must transcend internal rivalries between groups and the reflexes of administrative protectionism. ${ }^{(18)}$

- Liangguiheyi, or the attempted integration of two plans

The awareness of a need for coherence between plans gave rise to an attempt to integrate "two plans into one" or liangguiheyi (两规合一). This approach emerged essentially in academic circles and in an exploratory way, without political repercussions or conclusive results. The most concrete public initiative of this new paradigm was the administrative merger of the BoHURD ${ }^{(19)}$ and the BLR within the Municipality of Shanghai in October 2008. This step marked a significant advance towards the beginning of integration. ${ }^{(20)}$

- Sanguiheyi, or the advent in force of the NDRC

The paradigm of three-in-one integration, sanguiheyi (三规合一), followed closely on liangguiheyi. In short, its development exceeded liangguiheyi both in its actual attempts at implementation, and in the richness of its content.

Contrary to the direction taken in liangguiheyi, under the impetus of the NDRC, sanguiheyi adopted a more experimental approach from the outset, via pilot projects.

In Qinzhou in the Guangxi Zhuang Autonomous Province, the provincial DRC took the initiative in 2003 of proposing sanguiheyi-type planning, bringing together the plans for economic and social development, land-use, and planning, along with their coherence and coordination. This Qinzhou initiative very quickly received approval from the NDRC. The latter launched similar initiatives in October of the same year in six "pilot planning reform cities," including Qinzhou. However, due to the multiplicity of administrations involved, and the lack of tangible technical measures and legal safeguards, this initiative was not followed up.

In 2007, the Autonomous Municipality of Chongqing was chosen by the central government as an area for experimentation of reforms in planning to integrate rural and urban areas. Backed by an order from the central government, the initiative allowed the municipality to undertake in-depth reform of local planning mechanisms. First, it placed urban and rural planning at the centre of the integration process, thus achieving a new experiment in sanguiheyi. The urban planning services of the city thus offered a centralised "three-in-one" coordination of plans from its urban districts, and obtained political validation from the municipality. Following the successful 2007 experiment, in 2009 the Chongqing DRC proposed an action plan for the "integration of four superimposed plans," adding environmental protection to the three existing plans, echoing the objectives of "building an ecological civilisation" announced by the 17th National Congress of the CCP that same year. The new plan proposes an integrated vision of the four plans, following the logic of a five-year plan. (21) This experiment was noticed at

14. Wei Guangjun, "Duogui zhenghe yanjiu jinzhan yu pingshu" (Research Review on the Coordination of Spatial Planning), Chengshi guihua xuekan (Urban Planning Forum), No. 1, 2012, pp. 76-82.

15. Wang Lei, "Wunian jihua guihua chengshi guihua he tudi guihua de guanxi yanbian" (Evolution of the relationship between five-year socio-economic planning, rural and urban planning and land use planning in China), Chengshi guihua xuekan (Urban Planning Forum), No. 3, 2014, pp. 45-51.

16. Jean-François Doulet, "Chinese urbanism and the emergence of the 'integrationist' model," Métropolitiques, 27 April 2015, p. 2, http://www.metropolitiques.eu/L-urbanisme-chinois-et-lemergence.html (accessed on 12 December 2016).

17. Qian Ming, "Lun tudi liyong zongti guihua he chengshi zongti guihua de xietiao yu xianjie" (Integration of master planning plans and land use plans), Zhongguo tudi kexue (Chinese Territorial Science), Vol. 11, No. 5, 1997, pp. 1-5.

18. Lü Weijuan, "Chengshi zongti guihua yu tudi liyong zongti guihua yitongdian chutan" (Analysis of the coordination between the urban plan and the plan of full use of the soils), Chengshi guihua, (Urban Planning), No. 1, 1998, pp. 34-36.

19. For local administrative levels, we will use the following abbreviations: BDRC: Bureau or Commission for Reform and Development; BLR: Local Resources and Territory Office; BoHURD: Local Housing and Construction Bureau; BEP: Office of Environmental Protection at the local level.

20. Hu Jun, "Guihua de biange yu biange de guihua - Shanghai chengshi guihua yu tudi liyong guihua 'liangguiheyi' de shijian yu sikao" (Urban planning reform: practice and reflection on the coordination of the urban plan and land use plan in Shanghai), Chengshi guihua (Urban Planning), Vol. 34, No. 6, 2010, pp. 20-25.

21. Yu Jun and Yi Zheng, "Zonghexing kongjian guihua bianzhi tansuo - yi Chongqingshi chengxiang guihua bianzhi gaige shidian weili" (Global combination of space planning: the experience of ruralurban plan in Chongqing), Guihuashi (Planners), Vol. 25, No. 10, 2009, pp. 90-93. 
the central level, inaugurating a new stage in the integration of "several plans into one."

\section{The advent of duoguiheyi}

Duoguiheyi appears for the first time in an official text in 2014 in the "National Plan for a new urbanisation of cities and towns." This new vision of urban planning, which now has the further task of considering the countryside, also stresses the need for greater coordination between economic and social development plans, town planning, and land use under certain conditions and in some pilot areas of the country.

Following this, the NDRC, MoHURD, MLR, and MEP announced an action plan to test duoguiheyi all over China, again through pilot projects. The spirit that animates this work is experimental. The objective is to propose concrete ways of integrating the four types of plans, in order to obtain a replicable model that can be disseminated throughout the country, with the aim of "unique planning for each city."

In 2015, the "Proposal for Institutional Reform for the Construction of an Ecological Civilisation" (22) also recommended applying duoguiheyi unilaterally, with the aim of unifying the system of plans linked to space and territories, emphasising the innovation to be brought to planning methods.

Two years after its launch, the local administrations in charge of these pilot programs officially completed the duoguiheyi experiments. However, the degree of integration is not considered satisfactory. ${ }^{(23)}$ Duoguiheyi has not lead to a genuine sectorial "un-islanding," but rather has resulted in reinforced coordination without real integration. Despite the commitment of the central government, integration work is not necessarily evident in practice.

\section{Intrinsic technical inconsistencies}

The great majority of Chinese publications on duoguiheyi concentrate on the technical aspects of this integration and the problems caused by the multiplicity of plans: inconsistencies in their elaboration, legal frameworks, discrepancies in their duration of application, overlapping competences within city authorities, (24) hierarchical inequality of authorities, validation processes, unequal implementation efforts by administrations, ${ }^{(25)}$ as well as sectorial interference intrinsic to the very multiplicity of plans. (26) Problems related to inconsistencies in the dates of promulgation or between plans have resulted in conflicting land use, making it difficult to implement duoguiheyi. (27)

Opinions thus converge on the harmful effects of the multiplicity of plans, but diverge on how to integrate them. (28) From a technical point of view, it is difficult to decide on the predominance or legitimacy of one type of plan over the others. In reality, the inconsistencies between plans also reflect the balance of power between the actors representing each administration. The latter seek to legitimate their actions through their own technical arguments, putting forward an intrinsic rationality that reinforces their "superiority" over other administrations.

\section{Duoguiheyi and urban growth}

The evolution of Chinese urban growth is a key to understanding the political agenda that dictates the emergence of duoguiheyi.

In the 2000s, as land resources became marketable and thus a main source of financing for local and regional authorities in China, the plans put in place by local governments suddenly became the focus of special attention. At the central level, the tax reform of 1994 saw the tax contribution of planning increase, with local governments becoming increasingly dependent on the central government. For the central government, planning then became a tool for the orientation and management of the localities. During this period, although urban planning had a closer relationship to economic and social development, duoguiheyi was not yet a key word in priority discourses.

Since city planning and land-use plans had a stronger connection with the commercialisation of land, conflicts between these two schemes quickly became obstacles to development. These problems could be solved at the local level by the administrative merging of departments without hindering urbanisation, so duoguiheyi still did not attract the attention of the central government.

Duoguiheyi won recognition in 2014, when the central government began to speak of "New Urbanisation" and "New Normality." It was when the construction of cities and economic growth encountered structural difficulties that the central government finally decided to undertake a reform of the institutional planning system by granting it wider prerogatives and higher ranking in order to maintain and even reinforce its control of development at the local level.

\section{Technical trajectories of integration}

\section{The supremacy of urban planners}

Urban planning justifies its scientific legitimacy by the intrinsically integrative nature of the different disciplines of town planning, its action in space, and the durability of planning. Thus, Chinese urban planners support the idea that controlled integration of other sectors within urban planning is enough to make duoguiheyi successful. (29) With the emergence of sanguiheyi, some experts have begun to promote a more efficient, rational, and pragmatic method of application: using the urban planning system as a reference technical platform, integrating the contents related to land use on a regional

22. Central Committee of the CCP and State Council, Shengtai wenming tizhi gaige zongti fang'an (Proposal for institutional reform for the construction of an ecological civilisation), 21 September 2015, http://www.gov.cn/guowuyuan/2015-09/21/content_2936327.htm (accessed on 12 December 2016).

23. "Chengshiguihua 'duoguiheyi' zhenghe nan, yiyou 28 cheng shuaixian tansuo" (The integration of "several plans" into one in difficulty, experimentation launched in 28 pilot cities), Caixinwang (Journal of Financial Information), 10 May 2016, http://china.caixin.com/2016-0510/100942003.html (accessed on 30 May 2016).

24. Chen Wen, Yan Dongsheng, and Sun Wei, "Shixian 'duoguiheyi' yu gaige chuangxin: wenti, tiaozhan, yu lujing guanjian" (Reform and innovation on the integration of multiple plans: issues, challenges and the way forward), Guihuashi (Planners), Vol. 31, No. 2, 2015, pp. 17-22.

25. Su Han and Chen Hao, "'Duoguiheyi' de benzhi ji qi bianzhi yaodian tanxi" (The essence and key points of analysis of the integration of multiple plans), Guihuashi (Planners), Vol. 31, No. 2, 2015, pp. 57-62.

26. Shang Yanran, Yu Ting, Feng Yu, Zhang Yue, and Fu Shihua, "Qian fada diqu xianji duoguiheyi guihua shijian yu yanjiu" (Theory and practice of the integration of "Several plans in one" in disadvantaged cantons), Beijing guihua jianshe (Urbanism and Construction of Beijing), No. 6, 2015, pp. 40-42.

27. Lai Shouhua, Huang Huiming, Chen Jiaping, and Chen Xiaoming, "Cong jishu chuangxin dao zhidu chuangxin: Heyuan, Yunfu, Guanzhou sanguiheyi shijian yu sikao" (From technical innovation to institutional innovation: "three-plan coordination" in practice in Heyuan, Yunfu, and Guangzhou), Chengshi guihua xuekan (Urban Planning Forum), No. 5, 2013, pp. 63-68.

28. Gu Chaolin, "Lun Zhongguo 'duogui' fenli yuqi yanhua yu ronghe wenti" (On the separation of urban development plans in China, their evolution and their integration), art. cit., p. 610.

29. Xu Donghui, "'Sanguiheyi' de shiyu chengxiang zongtiguihua" (A master plan for "three in one" rural-urban integration), Chengshi fazhan yanjiu (Research in Urban Development), Vol. 21, No. 8, 2014, pp. 30-36. 


\begin{tabular}{|c|c|c|c|c|}
\hline $\begin{array}{c}\text { Planning } \\
\text { typology }\end{array}$ & $\begin{array}{c}\text { National planning for economic } \\
\text { and social development }\end{array}$ & General urban planning & National land-use planning & $\begin{array}{c}\text { Planning for Sustainable } \\
\text { Development and the } \\
\text { Environment }\end{array}$ \\
\hline $\begin{array}{c}\text { Affiliated } \\
\text { Ministry }\end{array}$ & $\begin{array}{c}\text { National Development and } \\
\text { Reform Commission (NDRC) }\end{array}$ & $\begin{array}{c}\text { Ministry of Housing and Urban- } \\
\text { Rural Development (MoHURD) }\end{array}$ & $\begin{array}{c}\text { Ministry of Land and Resources } \\
\text { (MLR) }\end{array}$ & $\begin{array}{c}\text { Ministry of Environmental } \\
\text { Protection (MEP) }\end{array}$ \\
\hline $\begin{array}{c}\text { Legal framework } \\
\begin{array}{r}\text { Period of application } \\
\text { of plan }\end{array}\end{array} \quad$ Constitution & Urban and Rural Development Act & Territorial Management Act & Environmental Protection Act \\
\hline $\begin{array}{r}\text { Validation authority } \\
\text { Legal force in }\end{array}$ & Local People's Assembly & $\begin{array}{c}\text { Provincial Government } \\
\text { (or State Council) }\end{array}$ & $\begin{array}{c}\text { Provincial Government } \\
\text { (or State Council) }\end{array}$ & Local People's Assembly \\
\hline implementation & Advisory and binding & Binding & Obligatory & Binding \\
\hline Nature of planning & Generalist & Generalist & Specialised & Specialised \\
\hline
\end{tabular}

scale, and bringing in elements of economic and social planning. ${ }^{(30)}$ The aim is to produce an "enhanced version" of rural-urban integration planning. (31) Urban planners insist, in particular, on the technical necessity of producing a "single synthesis plan," with a scale of action that would be at the level of the control plan ${ }^{(32)}$ or of the detailed plan, ${ }^{(33)}$ rather than on a duoguiheyi scale model of the master plan. As the latter have to be approved by urban planning authorities, MoHURD urban actors thus assert their legitimacy in driving the duoguiheyi, both from the point of view of technical rationality and from the point of view of the perimeter of legal competence.

\section{An approach more closely based on macro-economic strategy at the NDRC}

In the NDRC sector, experts in charge of economic and social planning are aware that they are not legitimate enough to act on space. Their action in duoguiheyi is therefore on a more strategic scale at the level of city master plans. ${ }^{(34)}$ The NDRC sector will thus put forward general strategic planning "upstream," followed by a plan for the coherence of the distribution of territorial resources, and an associated spatial control plan. In this way, the NDRC sector draws up a plan of plans in a " $1+3+X$ " hierarchy. It is thus at the centre of the development of the overall strategic plan. The latter is then supplemented by three other plans: urban and rural integration, land use, and environmental protection. The addition of other plans $(X)$ is then possible. On the development of the "single synthesis plan," the NDRC proposals focus more on principles than on technical aspects, with three spatial typologies at the heart of this plan: urban spaces, agricultural spaces, and ecological spaces. This map of regional spatial functionalities forms the framework within which plans for economic development, urban and rural integration, land use, and environmental protection are inserted. This framework therefore produces an integrated "roadmap." The final plan summarises in the form of "control lines" the physical and regulatory spatial boundaries for the protection of agricultural areas, environmental protection, urban development, and economic activities.

\section{The barely audible voice of the MLR experts and the tardiness of the MEP}

Experts in the land use sector propose starting from the national landuse plan to establish a spatial system of land use to be re-evaluated every five years in order to ensure coordination with economic and social development plans, which also last five years. However, due to the stagnation of actions in this sector, no national land use planning has been proposed since the mid-1990s. The well-known absence of planning techniques adapted to the modern needs of spatial development results in the low probability that duoguiheyi will be implemented in the territorial sector.

The least powerful of the four administrations concerned by duoguiheyi is certainly the MEP. From a political point of view, the MEP was elevated to the rank of Ministry only in 2008. It was previously a mere administration. The NDRC also cumulates the most important prerogatives in the field of environmental protection, such as international climate negotiations. Environmental planning is often relegated to a secondary level. It is considered "specialised," with little impact on space and insufficiently mature technical content. Under present conditions, the MEP cannot claim the role of director of duoguiheyi. Experts from the MEP branch express a preference for urban planning in the construction of duoguiheyi. Environmental planning is based on the principles of sustainable development in order to strengthen the protection of environmental resources and reduce the impact of urban and regional development on the environment. (35)

Some writers try to achieve all-encompassing syntheses of spatial planning, for example, a "model with three-dimensional objectives," (36) in which spatial planning must at one and the same time emphasise economic growth, ensure improvement of social conditions, and meet environmental and ecological protection objectives. This type of approach proposes a sys-

30. Dong Zuoji,"'Duoguiheyi': zhaozhun fangxiang lantu" (The integration of plans: the need to choose the right direction to establish a clear roadmap), Guotu ziyuan (National Land Resources), No. 6, 2015, pp. 11-14.

31. Zhang Quan and Liu jian, "Chengzhen tixi guihua gaige chuangxin yu 'sanguiheyi' de guanxi - cong 'sanjie gou yi wangluo' tanqi" (Relationship between reform and innovation of the planning of the urban system and integration of the three plans: three structures and a network in the planning of the urban system), Chengshi guihua (Urban Planning), Vol. 38, No. 10, 2014, pp. 13-27.

32. Control plan: urban development plan at the level of an urban district.

33. Detailed plan: urban development plan at the neighbourhood level within the urban borough.

34. Master plan: a general plan for the whole city.

35. Tang Yanqiu, Liu Dezhao, Li Jian, and Jiang Hongqiang, "Guanyu huanjing guihua zai 'duoguiheyi' zhongdingwei de sikao" (Reflection on the place of environmental planning in the integration of multiple plans), Huanjing baohu (Environmental protection), No. 7, 2015, pp. 55-59.

36. Fan Jie, Sun Wei, and Chen Dong, "Shiyiwu qijian diyukong jianguihua de keyichuangxin ji dui shierwuguihua de zhengcejianyi" (Scientific and technological innovations in space planning during the 11th Five-Year Plan and suggestions for the planning of the 12th Plan), Zhanlüe yu juece yanjiu (Strategy \& Policy Decision Research), No. 6, 2009, pp. 601-608. 
tem of values with fuzzy contours that, by seeking to please everyone, tends to render the planning apparatus invalid and inoperative. Others put forward models seeking to synthesise "2 major plans +5 minor plans" or "1 plan + 4 plans," (37) which mainly highlight the extent of the lack of coordination, but cannot attain general agreement.

It can thus be seen that none of these four administrations possesses technical ascendancy over the others. The success of this integration will depend greatly on the technical expertise of each actor.

\section{Lack of any convincing reference model}

The difficulties of setting up duoguiheyi thus arise from the current impossibility of its presentation in detail. There is as yet no real successful planning reference in China to date, so it is still too early to talk about successful concrete examples. At the institutional and legal level, as long as there is no political imperative, the competent authorities in each plan have no reason to change their current mode of operation, and therefore coordination has no effect.

The other difficulty remains technical: each plan concerns a different domain with differing technical references. Duoguiheyi must therefore innovate by introducing new technical references, which are by nature difficult to accept, and constantly trigger suspicion. The emergence of a new type of "winning" plan, which would succeed in integrating all the others, has not taken place either. The academic debates seem sterile, as long as the public authorities do not take them into account in their actions.

The Chinese central government admittedly has the power to impose integration by force, but the problem lies in the lack of a recognised and effective model of integration. While the various sectors bring to bear considerable lobbying efforts to defend duoguiheyi, they serve the interests of their own state bodies as a matter of priority, and thus will not be accepted by other sectors. The limited diversity of proposed alternatives prevents a valid model from emerging for all. This does not allow the central government to undertake in-depth reforms.

Moreover, even if a model is found, it is also necessary to develop crosssectional competencies and train a large number of qualified people, in order to implement the integration of plans at the national level. It will be a long road before duoguiheyi replaces all existing planning.

\section{Attempts at institutional innovation at the local level}

As a pillar of the institutional reform in progress, duoguiheyi necessarily produces a readjustment of the hierarchical relationships among those involved in planning. From the beginning of duoguiheyi, many departments of various administrations have been assigned new functions. These reforms have made possible the emergence of stronger and more powerful entities in the management of the integration of the plans, as part of a movement of administrative consolidation initiated by Chinese localities.

\section{Choosing a pilot entity}

The choice of a duoguiheyi pilot entity is the most frequent and least restrictive way of regulating the various powers. In the course of detailing planning, the sectoral specificities of the pilot entity are necessarily reflected in the content of the proposed planning for duoguiheyi. For example, the municipality of Chongqing awarded in 2007 the role of pilot of sanguiheyi to the MoHURD. In 2009, it was the municipal DRC that took charge of siguiheyi.

As a differentiating element, the DRC put forward in particular an alignment of the duration of the siguiheyi plan on a five-year basis, with more significant inter-sectorial linkages and coordination, and action oriented towards the implementation of the plan. These adjustments are obviously of a non-technical nature: they reflect a stronger control of the municipal government over its administrations. Moreover, the municipal government can always decide to reassign the role of pilot to a particular administration. On the other hand, this mode of piloting duoguiheyi requires the real involvement of the other administrations concerned. If the collaboration remains superficial, duoguiheyi will quickly come to resemble purely formal work without tangible effect.

\section{Establishing a coordinating entity}

The establishment of a coordinating entity can be an alternative to this pitfall. Some Chinese local authorities, in addition to the choice of the pilot administration, thus establish a governing body that plays a coordinating role and oversees the action of duoguiheyi. The municipality of Guangzhou, for example, has set up a working group of municipal leaders for duoguiheyi, chaired by the mayor, in charge of coordinating and removing the major problems related to sanguiheyi. The group puts in place a system of regular working meetings in order to drive the process forward. Each urban district of the city organises its integration of the plans according to the same model, with the working group at the urban district level regularly reporting progress to the central working group of the municipality. ${ }^{(38)}$

\section{Consolidating planning functions}

Consolidation of planning functions within a new entity may be a solution. Some cities go further in order to solve the problems associated with "squabbling between plans" and to ensure the success of duoguiheyi. The city of Yunfu in Guangdong has thus created a commission for the development of municipal planning. This commission brings together the initial administrations of DRC, MoHURD, and MLR along with their associated planning, in order to reshape the development of sanguiheyi. The commission is also given the power to audit the progress of specific ancillary plans, as well as to verify its application and its practical implementation.

\section{Merging administrative departments}

Merging the administrative departments of planning entities has been adopted by major municipalities such as Shenzhen, Shanghai, and Wuhan, which have merged the MoHURD and MLR offices into a single Planning and Territory Office. This measure makes it possible, to a certain extent, to bring the functional attributes of the urban space into line while optimising the use of territorial resources at the regional level. Finally, operations of

37. Wang Xiangdong and Gong Jian, "'Duoguiheyi' shijiaoxia de zhongguo guihua tixi chonggou" (Rebuilding the planning system from the perspective of "integrating multiple plans" in China), Chengshi guihua xuekan (Urban Planning Forum), No. 2, 2016, pp. 88-95.

38. Lai Shouhua, Huang Huiming, Chen Jiaping, and Chen Xiaoming, "Cong jishu chuangxin dao zhidu chuangxin: Heyuan, Yunfu, Guanzhou sanguiheyi shijian yu sikao" (From technical innovation to institutional innovation: "three-plan coordination" in practice in Heyuan, Yunfu and Guangzhou), art. cit., p. 66. 


\begin{tabular}{|c|c|c|c|}
\hline Pilot city & Nature of the duoguiheyi & Technical component & Institutional change \\
\hline Shanghai & Two plans in one. & $\begin{array}{l}\text { Coherence of multi-discipline maps to draw a } \\
\text { single map. } \\
\text { A platform integrates management of urban } \\
\text { planning and approval of construction projects, } \\
\text { with the development of the "Single Synthesis } \\
\text { Plan". }\end{array}$ & $\begin{array}{l}\text { Merger of the MoHURD and MLR channels into a } \\
\text { single Bureau of Urbanism and Territory (2008). }\end{array}$ \\
\hline Guangzhou & Three plans in one. & $\begin{array}{l}\text { Integration of the three plans into one, based on } \\
\text { the Urban Development Strategic Master Plan. } \\
\text { Creation of a platform to accumulate spatial and } \\
\text { technical data. }\end{array}$ & $\begin{array}{l}\text { Establishment of a working group of municipal } \\
\text { leaders chaired by the mayor (2012). }\end{array}$ \\
\hline $\begin{array}{l}\text { Yunfu } \\
\text { (Guangdong) }\end{array}$ & Three plans in one. & $\begin{array}{l}\text { Objectives and years standardised for the } \\
\text { development of plans. } \\
\text { Integrated database platform. }\end{array}$ & $\begin{array}{l}\text { Establishment of the commission preparing } \\
\text { and examining urban development plans. } \\
\text { Common method of decision-making, } \\
\text { implementation by level (2014). }\end{array}$ \\
\hline Chongqing & $\begin{array}{l}\text { Integrated approach at the municipal } \\
\text { level, and three plans in one at the } \\
\text { district scale. }\end{array}$ & $\begin{array}{l}\text { Objectives and validity of duration standardised } \\
\text { for the development of the plans. } \\
\text { Integrated computer database. } \\
\text { District-wide trial work. }\end{array}$ & $\begin{array}{l}\text { Pilot planning by a single establishment. } \\
\text { Consistency between the duration of the master } \\
\text { plan and the mandate of the managers (2009). }\end{array}$ \\
\hline $\begin{array}{l}\text { Foshan } \\
\text { (Guandgong) }\end{array}$ & Three plans in one. & $\begin{array}{l}\text { Platform for integration of spatial statistics } \\
\text { and information. }\end{array}$ & $\begin{array}{l}\text { Large-scale administrative reform: merger of } \\
\text { DRC, MoHURD and MLR into a new Municipal } \\
\text { Bureau of Development, Planning and Statistics } \\
\text { to develop uniform plans (2012). }\end{array}$ \\
\hline
\end{tabular}

"large-scale administrative reform" have been initiated in Foshan, Guangdong Province. The city has merged the units of the DRC, the BoHURD, and Statistics into a new entity at the level of the five urban districts. The new Bureau of Development Planning and Statistics is entrusted with the expanded task of preparing the master plan, and the plans for economic and social development, land use, and environmental protection, as well as their integration. It is in this city that administrative reform has gone the furthest to bring about duoguiheyi.

In reality, duoguiheyi is progressing pragmatically on the ground. Under pressure from land development, urban planning and territorial resource planning have already found an "agreement" on the ground, with the process of co-ordination already well underway. With the unification of the planning and territorial services of the city of Beijing in August 2016, all of the autonomous municipalities of China have taken the step of guituheyi (规土合一), (39) the foundation of first-degree coordination that can lead to integration.

\section{Building "ecological civilisation" by duoguiheyi?}

In parallel with the local policies of duoguiheyi, there appeared in the noughts the "sustainable city" movement in China, which was also concomitant with the internationalisation of the country and its integration into globalisation. As it is inclusive in its approach, the planning of the sustainable city to some extent advocates a form of planning integration. The 13th Five-Year Plan now speaks of "Ecological Civilisation and Green Development," (40) and seems to designate duoguiheyi as the main tool for its realisation.

\section{"Ecological civilisation," a privileged area of application of duoguiheyi}

In September 2015, the highest central government authorities, the Party Central Committee and the State Council, jointly published the "Comprehensive Program of Institutional Reform for the Construction of the Ecological Civilisation," (41) which aims to "build institutional governance at the national level" with a panel of innovative measures broken down into "eight systems," which are:

1) a system of land ownership based on the availability of natural resources; 2) a spatial protection system for the development of the national territory; 3) a spatial planning system; 4) a system of unilateral, economical, and regulated management of resources; 5) a system of exploitation of these resources conditioned by ecological debt; 6 ) a regulated environmental management system; 7 ) a system for the protection of the ecology in the context of a market economy; and 8) a system for the evaluation of performance and civil liability. ${ }^{(42)}$

Building on these eight systems, this governance "clarifies the ownership of resources, encourages pluralistic stakeholder involvement, systematically

39. Integration of urban planning services with territorial resources, which is equivalent to the integration of the first two liangguiheyi plans.

40. Central Committee of the Party and State Council, Shisanwu guihua jianyi (quanwen) (Recommendations for the 13th Five-Year Plan [full text]), 3 November 2015, http://www.moa.gov.cn/ zwllm/zcfg/flfg/ 201511/t20151103_4888538.htm (accessed on 30 May 2016).

41. Central Committee of the CCP and State Council, Shengtai wenming tizhi gaige zongti fang'an (Proposal for institutional reform for the construction of an ecological civilisation), op. cit.

42. Ibidem. 
encourages and regulates institutions, and allows the modernisation of the country's governance in striving towards a new era of the socialism of ecological civilisation." (43) This phrase appears no less than six times in the same text, thus becoming the new political watchword. The chapters describing the space planning system expressly mention that "cities and districts should promote duoguiheyi, bringing innovation in spatial planning." Duoguiheyi has thus become "a major institutional link in the construction of ecological civilisation," the construction of which passes "necessarily by support of duoguiheyi."

\section{Similarities in approaches}

Based on the 1994 Aalborg Charter, the principles of the sustainable city presuppose an integrated approach in the planning of the various urban systems that make up the city: transport, energy, water, etc. Moreover, a technical dimension is required in the form of systems of performance indicators. The technological character of the "sustainable city" would put it in the family of "progressive urban utopias," even if by essence the concept of "sustainable city" belongs more obviously to the "naturalistic" movement, according to the categories defined by Françoise Choay. ${ }^{(44)} \mathrm{Fi}-$ nally, to achieve the objective of the "sustainable city," collaborative and inclusive methods are also envisaged connected with the participation of the inhabitants.

It is interesting to note a certain convergence of the principles of duoguiheyi with the integrated approach of the urbanism of the sustainable city. In many respects, the emerging model of duoguiheyi described as "integrationist" (45) approaches a model of the "sustainable city" in the process of internationalisation. The Chinese doctrine of the "new urbanisation strategy" reprises the major normative fundamentals of the "sustainable city." (46) One of the major similarities is the use of performance indicator systems providing quantified objectives, which are systematically reflected in Chinese eco-city planning, both in the five-year plans developed by the NDRC and in city planning.

\section{Intrinsic resistance and background divergences}

While this vision espouses the global values of sustainable development, its implementation challenges the planning apparatus of the Chinese city in its striving for sectorial integration. Still at an exploratory stage, sustainable city projects at their current stage fail to convince experts of their viability. ${ }^{(47)}$ There is still a strong technical "silo" between the disciplines of town planning in China. The difficulties of integrating transport ${ }^{(48)}$ or energy in town planning ${ }^{(49)}$ reflect the inertia of the technical channels to collaborate, and constitute a similar obstacle to duoguiheyi.

There are also several fundamental differences between duoguiheyi and the integrated approach of the sustainable city. First, duoguiheyi in China generates a struggle between various professions to determine which will have the power to dominate the others, whereas the integrated approach is based on a comprehensive planning system that already incorporates different types of planning. In addition, duoguiheyi seeks to make one planning model dominate others, whereas the integrated approach seeks to reduce the number of plans through their integration. Finally, duoguiheyi in China is limited for the moment to four specifically identified fields, whereas the integrated approach does not impose any limits on itself. Talking about the advent of an integrated Chinese "model" (50) seems premature, as the first experiences of eco-city projects in China have been rather frustrated by the rigidity of administrative governance. ${ }^{(51)}$

\section{Conclusion}

As the new paradigm of institutional public action, the primary mission of duoguiheyi remains above all to resolve the conflict stemming from plans applied to the same space being drawn up independently of each other. It seeks to strengthen planning as an efficient tool for managing urban space. This integration policy is a challenge to institutions, for it requires reorganising the centre of power, which inevitably leads to a decomposition of state bodies that the major ministries are not necessarily willing to concede. The difficulties of its realisation are inherent to the pyramidal structure of the regime.

At the political level, this institutional movement also reveals the tendency towards a greater concentration of powers on the part of the current Chinese leadership. While duoguiheyi has not yet achieved the technical aspects of its integration, it is nevertheless, as an administrative measure, a formidably effective tool of political control. In reality, this struggle between state departments allows the political authorities at all levels to maintain control over their administrations. The illusion of the delegation of power in China is only more strongly reinforced: thanks to planning being made virtually impossible, the central government can intervene at the local level directly and at any moment.

The reasons for the blockage may also be due to the mismatch between this measure and the stage of development of the country. While China has not yet completed its urbanisation, ${ }^{(52)}$ any measure that seeks to curb this "runaway high-speed train" (53) seems illusory. The disparity between duoguiheyi and the values of sustainable development also shows the limitations of the Chinese "integrationist" model in search of legitimacy. As long as Chinese urbanisation remains subject to a "developmentalist" logic and fundamental reforms are not made at the level of the institutional regime, duoguiheyi is destined to become merely one more category of plans to be added to the existing "layer cake."

Finally, it should be recalled that duoguiheyi does not yet have force of law in China: it is a measure that is only at the beginning of its experimen-

43. Ibid.

44. Françoise Choay, L'Urbanisme, utopie et réalité, Seuil, Paris, 1965.

45. Jean-François Doulet, "L'urbanisme chinois et l'émergence du modèle 'intégrationniste,"' art. cit., p. 4.

46. Claire Carriou and Olivier Ratouis, "Quels modèles pour l'urbanisme durable?," Métropolitiques, 25 June 2014, www.metropolitiques.eu/Quels-modeles-pour-l-urbanisme.html (accessed on 30 May 2016).

47. Rémi Curien, "L'éco-cité de Tianjin: innovations et limites d'une conception sino-singapourienne d'une ville durable," Métropolitiques, 30 March 2016, http://www.metropolitiques.eu/L-ecocitede-Tianjin-innovations.html (accessed on 30 May 2016).

48. Aurélien Delpirou, Jean-François Doulet and Zhuo Jian, "Coordinating urban planning and public transport: a benchmark in the face of the city 'made in China,"' Flux, No. 101/102, July-December 2015, pp. $42-56$.

49. Long Weiding, "Chengqu xuqiuce nengyuan guihua" (Demand-driven urban energy planning), Nuantong Kongtiao (HVAC), No. 2, 2015, pp. 60-67.

50. Jean-François Doulet, "Chinese urbanism and the emergence of the 'integrationist' model," Métropolitiques, 27 April 2015, http://www.metropolitiques.eu/L-urbanisme-chinois-et-lemergence.html (accessed on 12 December 2016).

51. Rémi Curien, "Chinese Urban Planning: Environmentalising a hyper-functionalist machine?," China Perspectives, 2014/3, pp. 23-31.

52. The UNDP estimates that there will still be 300 million new urban residents by 2030 .

53. Rémi Curien, "Chinese Urban Planning: Environmentalising a hyper-functionalist machine?", art. cit., p. 30 
tation. But its promulgation marks a paradigm shift in the planning system (if not a revolution), and it will be even more important to evaluate how it stands the test of time. In any case, the evolution of duoguiheyi already reflects a process of struggle and the sharing of the power of planning expertise between the various administrations concerned, and a reaffirmation, on the part of the political authorities, of power over their technical departments.

I Translated by Michael Black

I Martin Tzou is an architect and urban planner graduated from the University of Louvain, Belgium. Based in Beijing, he is working on urban, energy and low-carbon planning projects in China.

Room 712, Henderson Centre, Office Tower 1, 18 Jianguomen Neidajie, Dongcheng District, 10005, Beijing, China

(martintzou@gmail.com).

I Du Shu is a state urban planner and head of Studio 3, at the China Centre for Urban Development affiliated with the NDRC.

5 East Sanlihe Rd, Xicheng District, 100045, Beijing, China (dushu@ccud.org.cn).

I Liu Lidan is a doctoral candidate in Geography at Université Paris I - Sorbonne.

Institut de Géographie, 191 rue Saint-Jacques, 75005 Paris (lidanliu1986@gmail.com).

Manuscript received on 6 June 2016. Accepted on 7 December 2016. 